\title{
ANALISIS KESIAPAN PEMBELAJARAN E-LEARNING SAAT PANDEMI COVID-19 DI SMK NEGERI 1 TAMBELANGAN
}

\section{ANALYSIS OF E-LEARNING READINESS DURING THE COVID-19 PANDEMIC AT SMK NEGERI 1 TAMBELANG}

\author{
Syamsul Jamal \\ SMK Negeri 1 Tambelangan \\ Samsul60175@yahoo.com
}

\begin{abstract}
The purpose of this study was to find out how e-learning Learning Readiness during the COVID-19 pandemic at SMK Negeri 1 Tambelang in six aspects of readiness (student readiness, teacher readiness, infrastructure readiness, management support, school culture, and trends in face-toface).The E-Learning Readiness model used in this study is the Teddy \& Swatman Model (2006) using six readiness factors. The six factors are the readiness of students, teacher readiness, infrastructure, management support, school culture and the tendency of face-to-face learning. Student readiness factor obtained value of 3,8 on scale of 5. According to the table of ranges of values and categories (Aydin \& Tasci 2005: 2015) that with these values is declared ready but requires a slight increase. Teacher readiness factors, management support factors and School Culture Factors score of 4.2. According to the table of ranges of values and categories (Aydin \& Tasci 2005: 2015) that with these values ready for the application of e-learning can be continued. Only 1 factor that is not ready and needs improvement is the e-learning tendency factor with an ELR value of 3.3
\end{abstract}

Keywords: e-learning, e-learning readiness

\begin{abstract}
Abstrak
Tujuan dalam penelitian ini adalah untuk mengetahui bagaimana Kesiapan Pembelajaran e-learning saat pandemic COVID-19 di SMK Negeri 1 Tambelangan dalam enam aspek kesiapan (kesiapan peserta didik, kesiapan guru, kesiapan infrastruktur, dukungan managemen, budaya sekolah, dan kecenderungan terhadap tatap muka). Model E-Learning Readiness yang digunakan dalam penelitian ini adalah Model Teddy \& Swatman (2006) menggunakan enam faktor kesiapan. Enam faktor tersebut adalah kesiapan peserta didik, kesiapan guru, infrastruktur, dukungan managemen, budaya sekolah dan kecenderungan pembelajaran tatap muka. Faktor kesiapan peserta didik diperoleh nilai sebesar 3,8 dalam skala 5. Menurut tabel rentang nilai dan kategori (Aydin \& Tasci 2005 : 2015) bahwa dengan nilai tersebut dinyatakan siap tetapi membutuhkan sedikit peningkatan. Faktor kesiapan guru, Faktor dukungan management serta faktor budaya sekolah diperoleh nilai sebesar 4,2. Menurut tabel rentang nilai dan kategori (Aydin \& Tasci 2005 : 2015) bahwa dengan nilai tersebut siap penerapan e-learning dapat dilanjutkan. Hanya 1 faktor yang tidak siap dan perlu peningkatan adalah Faktor Kecenderungan pembelajaran e-learning dengan nilai ELR sebesar 3,3
\end{abstract}

Kata Kunci : e-learning, e-learning readiness

\section{PENDAHULUAN}

Kementerian Pendidikan dan Kebudayaan (Kemendikbud) selaku leading sektor pendidikan nasional yang berperan penting dalam mewujudkan kualitas SDM Indonesia, menindaklanjutinya dengan mengeluarkan berbagai kebijakan penting, diantaranya kebijakan pendidikan "Merdeka Belajar", yang digulirkan oleh Mendikbud Nadiem Anwar Makarim [1].
Konsep Merdeka dan Belajar menurut hemat penulis dapat dipersepsikan sebagai upaya untuk menciptakan suatu lingkungan belajar yang bebas untuk berekspresi, bebas dari berbagai hambatan terutama tekanan psikologis. Bagi guru dengan memiliki kebebasan lebih fokus untuk memaksimalkan pada pembelajaran guna mencapai tujuan (goal oriented) pendidikan nasional, namun tetap dalam rambu kaidah kurikulum. Bagi 
siswa bebas untuk berekspresi selama menempuh proses pembelajaran di sekolah, namun tetap mengikuti kaidah aturan di sekolah. Siswa bisa lebih mandiri, bisa lebih banyak belajar untuk mendapatkan suatu kepandaian, dan hasil dari proses pembelajaran tersebut siswa berubah secara pengetahuan, pemahaman, sikap/karakter, tingkah laku, keterampilan, dan daya reaksinya, sejalan dengan apa yang diamanatkan dalam tujuan UU Sisdiknas Tahun 2003, yakni; untuk mengembangkan potensi peserta didik agar menjadi manusia yang beriman dan bertakwa kepada Tuhan Yang Maha Esa, berakhlak mulia, sehat, berilmu, cakap, kreatif mandiri, dan menjadi warga negara yang demokratis serta bertanggungjawab [2].

Memasuki pertengahan bulan maret yaitu tanggal 16 maret 2020 masa jaga jarak atau physical distancing dalam menghadapi pandemi Covid-19 ini diberlakukan di wilayah seluruh Provinsi Jawa Timur, membuat banyak sekolah diliburkan, sehingga anak belajar dan beraktivitas di rumah. Namun, ini bukan berarti hanya tinggal diam dan duduk manis di rumah. Aktivitas belajar tetap harus dilaksanakan antara pendidik dan peserta didik. Keadaan ini memaksa melakukan interaksi secara digital untuk menyapa peserta didik dan memberikan materi dan tugas yang harus siswa lakukan di rumah. Jika setiap pendidik dan peserta didik mampu melakukannya bersama, maka proses belajar mengajar tetap dapat terlaksana dengan baik. Menyikapi kondisi stay at home akibat pandemi Covid19, guru benar-benar harus mampu menyajikan pembelajaran dengan menggunakan teknologi atau biasa kita sebut dengan pembelajaran e-learning .

Namun tidak serta merta pembelajaran online dapat langsung digunakan dalam suatu lingkungan sekolah, berhasil tidaknya pencapaian tujuan pendidikan banyak bergantung kepada proses belajar yang dialami peserta didik. Ref. [3] mengungkapkan dalam proses belajar yang berpengaruh bagi tujuan pendidikan yang berlangsung salah satu faktor psikologi yang ada didalamnya adalah kesiapan.

Kesiapan adalah keseluruhan kondisi seseorang yang membuatnya siap untuk memberi respons/jawaban di dalam cara tertentu terhadap suatu situasi [3]. Kesediaan untuk memberi respons atau bereaksi. Kesediaan itu timbul dari dalam diri seseorang dan juga berhubungan dengan kematangan, karena kematangan berarti kesiapan untuk melaksanakan kecakapan. Kesiapan ini perlu diperhatikan dala proses belajar, karena jika siswa belajar dan padanya sudah ada kesiapan, maka hasil belajarnya akan lebih baik [3].

Suatu pengembangan e-learning didalamnya terdapat proses analisis yang sangat penting yang akan menentukan langkah pengembangan selanjutnya. Kesiapan e-learning dikelompokkan menjadi enam faktor yaitu (1) kesiapan peserta didik (2) kesiapan guru (3) infrastruktur (4) dukungan managemen (5) budaya sekolah (6) kecenderungan pembelajaran tatap muka [4].

SMK Negeri 1 Tambelangan adalah salah satu sekolah menengah kejuruan yang sudah banyak dikenal di propinsi Jawa Timur khususnya di Kabupaten Sampang dengan prestasi dan fasilitasnya. Mengetahui tingkat kesiapan terhadap pembelajaran online yang akan diterapkan diharapkan sekolah dapat menentukan langkah selanjutnya yang akan diambil. Tingkat kesiapan pada setiap kategori yang diuji selain dapat mengetahui tingkat kesiapan secara keseluruhan, dapat diketahui juga kategori kesiapan yang masih rendah. Tingkat kesiapan pada kategori yang masih rendah akan ditindaklanjuti dan tingkat kesiapan pada kategori tinggi akan dipertahankan. Sehingga pihak sekolah dapat melakukan efisiensi dalam management sekolah.

Permasalahan dan tujuan dalam penelitian ini adalah untuk mengetahui bagaimana Kesiapan Pembelajaran $e$ learning saat pandemic COVID-19 di SMK Negeri 1 Tambelangan dalam enam aspek kesiapan (kesiapan peserta didik, kesiapan guru, kesiapan infrastruktur, dukungan 
managemen, budaya sekolah, dan kecenderungan terhadap tatap muka).

\section{E-learning}

E-learning merupakan segala aktivitas belajar yang menggunakan bantuan teknologi elektronik, yang dapat diaplikasikan dalam pendidikan konvensional dan pendidikan jarak jauh [5]. E-learning adalah kegiatan pendidikan atau pembelajaran melalui media elektronik [6]. Pendapat lain mengemukakan bahwa e-learning adalah metode pembelajaran baru berupa perpaduan antara teknologi jaringan dan multimedia yang dikawinkan dengan pedagogi dan andragogy [7]. E- learning merupakan pembelajaran yang memanfaatkan dukungan teknologi internet. Dalam e-learning, pengajar tidak sekedar menggunggah materi pembelajaran yang bisa diakses secara online oleh peserta didik, tetapi pengajar juga melakukan evaluasi, menjalin komunikasi, berkolaborasi, dan mengelola aspek-aspek pembelajaran lainnya [8].

Dalam pembelajaran e-learning terjadi interaksi yang melibatkan siswa, pengajar dan konten [7]. Interaksi siswa-siswa, interaksi siswa-konten, interaksi kontenkonten, interaksi pengajar-konten, interaksi pengajar-pengajar, dan interaksi pengajar siswa.

Wildavsky dalam Ref. [6] mengemukakan tentang kelemahan pembelajaran online yaitu minumnya frekuansi kontak dan sosialisai antar siswa dalam proses pembelajaran. E-learning yang dilakukan jarak jauh tentu akan mengurangi frekuensi kontak baik antar peserta didik atau peserta didik dengan guru karena dapat dilakukan pada ruang dan waktu yang berbeda sehingga sosialisasi yang dilakukan juga akan berkurang. Pendapat lain mengenai kelemahan E-learning dikemukakan dalam Ref. [9] yaitu mahalnya pengembangan dalam E-learning dan kurangnya waktu untuk mengikuti course dalam E-learning.

Beberapa kelemahan diatas dalam hal kurangnya sosialisasi peserta didik dapat diatasi dengan tugas yang diberikan oleh guru dalam pembelajaran dilakukan secara berkelompok, sehingga antar peserta didik dengan-dikelompokkan untuk mengerjakan tugas akan melakukan komunikasi lebih banyak dengan peserta didik yang lain. Kelemahan lain seperti mahalnya pengembangan dapat menggunakan framework yang disediakan secara gratis.

\section{E-Learning Readiness}

Model e-learning readiness banyak dikembangkan model yang dikemukakan dalam Referensi [10] adalah salah satu model readiness dengan tujuh kategori dalam penilaiannya. Ref. [11] mengemukakan beberapa komponen kesiapan penggunaan $E$ learning yaitu (1) kesiapan urusan (2) kesiapan teknologi (3) kesiapan pelatihan (4) kesiapan kultur (5) kesiapan manusia (6) kesiapan finansial.

E-learning readiness yang dikemukakan Ref. [12] menggunakan delapan kategori dalam penilaian kesiapan yaitu (1) psychological readiness yang mempertimbangkan cara pandang terhadap pengaruh inisiatif E-learning. faktor ini merupakan faktor penting yang harus dipertimbangkan dan memiliki peluang tertinggi untuk sabotase proses implementasi (2) sociosilogical readiness mempertimbangkan aspek interpersonal lingkungan dengan program yang akan diimplementasikan (3) environmental readiness yang mempertimbangkan operasi kekuatan besar pada stakeholders, baik dalam maupun luar organisasi (4) human resources readiness yang mempertimbangkan ketersediaan dan rencana system dukungan sumber daya manusia (5) finanscial readiness yang mempertimbangkan besarnya anggaran dan proses alokasi (6) technological skill readiness yang mempertimbangkan kompetensi teknis yang akan diamati dan diukur (7) equipment readiness yang mempertimbangkan kepemilikan peralatan yang sesuai (8) content readiness yang mempertimbangkan konten pembelajaran dan sasaran pembelajaran.

Penilaian kesiapan penggunaan $E$ learning juga dapat menggunakan model yang dikemukakan dalam Ref. [4] model ini banyak digunakan di negara berkembang dengan empat faktor yaitu teknologi, inovasi, manusia dan pengembangan diri. Model $E$ learning Readiness ini dapat digunakan untuk dapat menentukan tingkat kesiapan $E$ learning pada organisasi atau sekolah. 
Penjabaran faktor ELR yang dikemukakan dalam Ref. [4] adalah (1) faktor teknologi (2) faktor inovasi (3) faktor manusia (4) faktor pengembangan diri.

Ref. [13] mengemukakan terdapat model E-Learning Readiness yang dikemukakan oleh Teddy and Swatman. Dalam model yang dikembangkan Teddy \& Swatman, kesiapan penerapan E-learning dapat dilihat dari dua tingkatan pendidikan yaitu sekolah dasar dan sekolah menengah. Perbedaan guru wanita dan guru laki-laki juga menjadi pertimbangan dalam menentukan kesiapan E-learning, selain itu jurusan atau kelas yang ada dalam tingkatan sekolah khususnya sekolah menengah menjadi faktor kesiapan guru dalam menerapkan E-learning. Faktor yang dikemukakan lebih sederhana, terdiri dari enam faktor yang dijabarkan ke dalam 23 item. Enam faktor tersebut adalah sebagai berikut: 1. Kesiapan Peserta Didik, 2. Kesiapan Guru, 3. Kesiapan Infrastruktur, 4. Faktor Dukungan Management Sekolah, 5. Faktor Budaya sekolah, 6. Faktor Kecenderungan terhadap Pembelajaran Tatap Muka.

\section{METODE PENELITIAN}

Pendekatan yang digunakan dalam penelitian ini adalah pendekatan kuantitatif. Penelitian ini menggunakan metode penelitian deskriptif. Penelitian deskriptif adalah penelitian yang berusaha mendeskripsikan suatu gejala, peristiwa, kejadian yang terjadi pada saat sekarang [14]. Penelitian ini bertujuan untuk menggambarkan suatu keadaan kesiapan sekolah dalam penerapan e-learning di saat pandemic COVID-19.

Model yang digunakan dalam penelitian ini adalah model untuk mengukur kesiapan penerapan e-learning. Model Teddy \& Swatman menggunakan enam faktor kesiapan. Enam fator tersebut adalah kesiapan peserta didik, kesiapan guru, infrastruktur, dukungan managemen, budaya sekolah dan Kecenderungan pembelajaran $e$ learning Model ini akan memberikan skor atau nilai kesiapan pada tiap faktor dan kesiapan penggunaan E-learning di sekolah secara keseluruhan. Model ini cocok digunakan di Indonesia banyak dikembangkan untuk instansi- instansi di negara berkembang [13].

Penelitian ini dilaksanakan di SMK Negeri 1 Tambelangan yang dilaksanakan pada tanggal 23 -29 Maret 2020. Populasi dan sampel adalah sebanyak 28 guru yang terdaftar di web: https://dapo.dikdasmen.kemdikbud.go.id [15].

Penelitian ini menggunakan kuesioner yang berisi 34 pertanyaan. Pertanyaan berdasarkan model Teddy \& Swatman untuk enam faktor yaitu kesiapan peserta didik, kesiapan guru, infrastruktur, dukungan managemen, budaya sekolah dan kecenderungan pembelajaran tatap muka [13].

Semua pertanyaan akan dinilai menggunakan skala penilaian yang dikemukakan dalam Ref. [4]. Skala penilaian tersebut berupa empat kategori yaitu (1) Siap dan penerapan dapat dilaksanakan (2) Siap tetapi membutuhkan sedikit peningkatan (3) Tidak siap dan membutuhkan sedikit peningkatan (4) Tidak siap dan membutuhkan banyak peningkatan

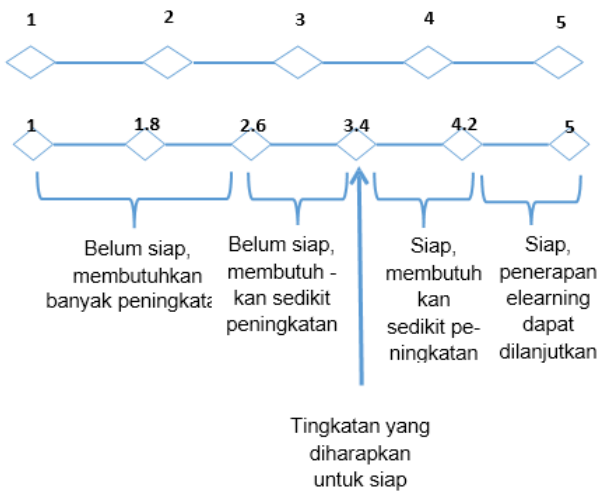

Gambar 1. Skala penilaian kesiapan pengunaan Pembelajaran e-learning

Tabel 1. Rentang Nilai dan Kategori [4].

\begin{tabular}{|l|l|}
\hline $\begin{array}{l}\text { Rentang } \\
\text { Nilai }\end{array}$ & Kategori \\
\hline $1 \leq x \leq 2,6$ & $\begin{array}{l}\text { Tidak siap, membutuhkan } \\
\text { banyak peningkatan }\end{array}$ \\
\hline $\begin{array}{l}2,6 \leq x \\
\leq 3,4\end{array}$ & $\begin{array}{l}\text { Tidak siap, membutuhkan } \\
\text { sedikit peningkatan }\end{array}$ \\
\hline $3,4 \leq x$ & Siap, tetapi membutuhkan \\
$\leq 4,2$ & sedikit peningkatan \\
\hline $4,2 \leq x \leq 5$ & $\begin{array}{l}\text { Siap, penerapan E- } \\
\text { learning dapat dilanjutkan }\end{array}$ \\
\hline
\end{tabular}

\section{HASIL DAN PEMBAHASAN \\ Uji Validitas dan Reliabilitas}

Uji validitas dan Reliabilitas instrumen diperlukan agar dalam pertanyaan kuisioner yang peneliti ajukan ke responden bisa 
dikatakan valid. Uji validitas dan realiabiitas menggunakan uji pearson product moment dengan software SPSS. Berikut tabel hasil uji validitas dan reliabilitas.

Tabel 2. Hasil uji validitas dan reliabilitas

\begin{tabular}{|c|c|c|c|c|c|}
\hline \multicolumn{6}{|c|}{ Item-Total Statistics } \\
\hline & $\begin{array}{l}\text { Scale Mean if } \\
\text { Item Deleted }\end{array}$ & $\begin{array}{l}\text { Scale Variance } \\
\text { if Item Deleted }\end{array}$ & $\begin{array}{l}\text { Corrected Item- } \\
\text { Total Correlation }\end{array}$ & $\begin{array}{l}\text { Squared } \\
\text { Multiple } \\
\text { Correlation }\end{array}$ & $\begin{array}{c}\text { Cronbach's } \\
\text { Alpha if Item } \\
\text { Deleted }\end{array}$ \\
\hline Q1 & 130,68 & 251,263 &, 721 & & ,968 \\
\hline Q2 & 130,86 & 252,127 & ,644 & &, 968 \\
\hline Q3 & 130,93 & 252,291 & ,616 & & 969 \\
\hline Q4 & 130,75 & 253,676 & ,691 & & 968 \\
\hline Q5 & 130,57 & 253,069 &, 590 & & 969 \\
\hline Q6 & 130,61 & 252,840 & ,577 & & ,969 \\
\hline Q7 & 130,64 & 251,497 &, 671 & & ,968 \\
\hline Q8 & 130,68 & 253,856 &, 656 & & ,968 \\
\hline Q9 & 131,11 & 243,581 &, 717 & & ,968 \\
\hline Q10 & 130,96 & 248,258 & ,652 & & ,969 \\
\hline Q11 & 130,43 & 251,587 &, 752 & & ,968 \\
\hline Q12 & 130,32 & 252,967 & ,776 & & ,968 \\
\hline Q13 & 130,39 & 249,655 & ,753 & & 968 \\
\hline Q14 & 130,39 & 250,840 &, 695 & & 968 \\
\hline Q15 & 130,36 & 252,312 & ,742 & & 968 \\
\hline Q16 & 130,36 & 253,275 & 688 & & ,968 \\
\hline Q17 & 130,32 & 254,152 & ,703 & & 968 \\
\hline Q18 & 130,43 & 250,476 &, 813 & & ,968 \\
\hline Q19 & 130,68 & 247,411 & ,649 & & 969 \\
\hline Q20 & 130,50 & 251,889 &, 718 & & ,968 \\
\hline Q21 & 130,57 & 246,476 &, 842 & & ,967 \\
\hline Q22 & 130,50 & 251,444 &, 742 & & ,968 \\
\hline Q23 & 130,57 & 251,810 & ,651 & & 968 \\
\hline Q24 & 130,50 & 250,111 & ,814 & & ,968 \\
\hline Q25 & 130,82 & 248,671 & ,625 & & ,969 \\
\hline Q26 & 130,43 & 248,921 &, 693 & & ,968 \\
\hline Q27 & 130,46 & 251,295 &, 719 & & ,968 \\
\hline Q28 & 130,43 & 251,069 & ,780 & & ,968 \\
\hline Q29 & 130,54 & 249,369 & ,808 & & ,968 \\
\hline Q30 & 130,61 & 249,951 & ,712 & & ,968 \\
\hline Q31 & 130,50 & 249,815 & 830 & & ,968 \\
\hline Q32 & 130,43 & 254,180 & 610 & & ,969 \\
\hline Q33 & 131,14 & 251,757 & ,439 & & 970 \\
\hline Q34 & 131,39 & 246,914 & 677 & & ,968 \\
\hline
\end{tabular}

Jumlah sampel adalah 28 maka DF $=\mathrm{N}-2$ $=28$ dengan probabilitas 0,05 maka didapat $\mathrm{R}_{\text {tabel }}$ sebesar 0,3172. Dari tabel untuk nilai corrected item-total correlation mempunyai nilai lebih besar dari $R_{\text {tabel }}$ sehingga 34 pertanyaan kuisioner tersebut dikatakan Valid. Sedangkan untuk uji reliabilitas instrumen menggunakan nilai Cronbach's Alpha if item deleted dimana semua nilai yang tersaji di tabel adalah lebih dari $\mathrm{R}_{\text {tabel }}$ sebesar 0,3172, sehingga reliabilitas keseluruhan instrumen sudah Valid.

\section{E-Readiness (ELR)}

Data yang diperoleh dari responden sebanyak 28 guru kemudian dianalisis dengan menggunakan model E-learning Readiness yang dikemukakan dalam Ref. [4]. Angket penelitian ini memiliki 34 pertanyaan dengan alternatif jawaban "Sangat Setuju" dengan skor 5, "Setuju" dengan skor 4, "Netral" dengan skor 3, "Tidak setuju" dengan skor 2, dan "Sangat Tidak Setuju" dengan skor 1 . Tujuan penggunaan angket pada penelitian ini adalah untuk mengetahui respon guru terhadap kesiapan penggunaan Pembelajaran e-learning di SMK Negeri 1 Tambelangan. Berikut kami sajikan data berupa grafik.

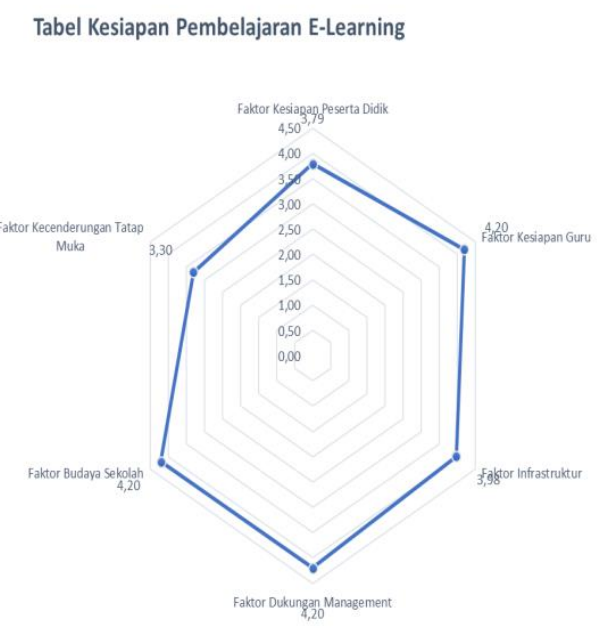

Gambar 2. Kesiapan Pembelajaran elearning di SMK Negeri 1 Tambelangan.

Faktor kesiapan peserta didik diperoleh nilai sebesar 3,793. Menurut tabel rentang nilai dan kategori bahwa dengan nilai tersebut dinyatakan siap tetapi membutuhkan sedikit peningkatan [4]. Dari 10 pertanyaan kuisioner yang perlu ditingkatkan adalah masih adanya siswa kesulitan mengakses internet dengan ELR sebesar 3,464 ini disebabkan letak geografis dari SMK Negeri Tambelangan berupa pegunungan sehingga masih ada letak blank signal. Selain itu yang perlu peningkatan adalah peserta didik perlu lebih intens kerjasama kelompok saat mengerjakan tugas harian pada pembelajaran e-learning dengan nilai ELR sebesar 3, 607. Dan juga pada faktor kesiapan siswa ini yang perlu ditingkatkan adalah pengaturan waktu dalam penggunaan e-learning dengan nilai ELR sebesar 3,643, sehingga guru masih 
perlu mengingatkan ke siswa agar selalu aktif dalam pengerjaan tugas harian di e-learning.

Aspek Kesiapan guru diperoleh nilai sebesar 4,2. Menurut tabel rentang nilai dan kategori Ref. [4] bahwa dengan nilai tersebut siap penerapan e-learning dapat dilanjutkan. Tetapi dari 10 pertanyaan kuisioner yang perlu diperhatikan adalah akses internet dengan nilai ELR sebesar 3,893. Letak geografis dari SMK Negeri 1 Tambelangan mempunyai pengaruh adanya blank signal.

Faktor Infrastruktur diperoleh nilai sebesar 3,979. Menurut tabel rentang nilai dan kategori dalam Ref. [4] bahwa dengan nilai tersebut dinyatakan siap tetapi membutuhkan sedikit peningkatan. Yang perlu ditingkatkan adalah kecepatan akses internet dengan nilai ELR sebesar 3,75. Sinyal akses internet masih terdapat blank signal dengan letak geografis yang tidak mendukung.

Faktor dukungan management dan budaya sekolah masing-masing diperoleh nilai sebesar 4,2. Menurut tabel rentang nilai dan kategori bahwa dengan nilai tersebut siap penerapan e-learning dapat dilanjutkan[4].

Faktor Kecenderungan pembelajaran $e$ learning diperoleh nilai sebesar 3,304. Menurut tabel rentang nilai dan kategori dalam Ref. [4] bahwa dengan nilai tersebut dinyatakan tidak siap tetapi membutuhkan sedikit peningkatan. Dari 2 pertanyaan yang diajukan memang untuk guru dan siswa masih perlu sosialisasi dan pelatihan tentang e-learning, sehingga untuk management sekolah memberikan waktu yang fleksibel untuk pelatihan e-learning dan sosialisasi untuk guru dan siswa.

\section{KESIMPULAN}

Berdasarkan hasil penelitian dan pembahasan tingkat kesiapan penerapan $e$ learning di SMK Negeri 1 Tambelangan, maka dapat disimpulkan bahwa SMK Negeri 1 Tambelangan memiliki hasil skor ELR 3,45 termasuk dalam kategori siap dalam penerapan e-learning, namun membutuhkan sedikit peningkatan pada beberapa faktor. 6 faktor yang diajukan menunjukkan 2 faktor siap namun membutuhkan sedikit peningkatan, 2 faktor tersebut adalah kesiapan peserta didik, dan kesiapan infrastruktur. Sedangkan 3 faktor siap penerapan e-learning dapat dilanjutkan. Ini merupakan modal dasar dalam kesiapan pembelajaran e-learnng saat pandemic
COVID-19 di SMKN 1 Tambelangan. 3 faktor tersebut adalah faktor kesiapan guru, faktor dukungan management dan faktor budaya sekolah dan satu faktor lainnya yaitu faktor Kecenderungan pembelajaran $e$ learning masuk dalam kategori tidak siap tetapi membutuhkan peningkatan.

\section{DAFTAR PUSTAKA}

[1]. Sekretariat GTK. (18 Februari 2020). Merdeka Belajar. Dikutip dari https://gtk.kemdikbud.go.id/readnews/merdeka-belajar

[2]. Kompas.com. 12 Desember 2019. Gebrakan Merdeka Belajar, Berikut 4 Penjelasan Mendikbud Nadiem. Dikutip dari https://edukasi. kompas.com/read/2019/12/12/125917 71/gebrakan-merdeka-belajar-berikut4-penjelasan-mendikbudnadiem?page $=$ all.

[3]. Slameto. (2013). Belajar dan FaktorFaktor yang Mempengaruhinya. Jakarta: Rineka Cipta

[4]. Teddy, \& Swatman, P. M. C. (2006). E-learning Readiness of Hong Kong Teachers. The Journal of Education Research University of South Australia

[5]. Rusman. (2013). Model-Model Pembelajaran. Jakarta: Rajagrafindo Persada.

[6]. Wena, M. (2009). Strategi Pembelajaran Inovatif Kontemporer. Jakarta: Bumi Angkasa.

[7]. Sutopo, A. H. (2012). Teknologi Informasi dan Komunikasi dalam Pendidikan. Yogyakarta: Graha Ilmu.

[8]. Surjono, D. H. (2013). Membangun Course E-learning Berbasis Moodle. Yogyakarta: UNY Press.

[9]. Schreurs, J., \& Al-Huneidi, A. M. (2012). E-Learning Readiness in Organizations. International Journal of Advanced Corporate Learning (iJAC), 5, 4-7.

[10]. Haney, D. (2002). Assessing Organizational Readiness for E- 
Learning: 70 Questions To Ask.

Performance Improvement, 41(4), 813. http://doi.org/10.1002/widm. 45

[11]. Saekow, A., \& Samson, D. (2011). Elearning Readiness of Thailand Universities Comparing to the USA's Cases. International Journal of $E$ Education, E-Business, EManagement and E-Learning, 1(2), 126-131.

[12]. Chapnick, S. (2000). E-Learning Readiness Assessment. Retrieved January 1, 2016, from http://www.researchdog.com.

[13]. Teddy, \& Swatman, P. M. C. (2006). E-learning Readiness of Hong Kong Teachers. The Journal of Education Research University of South Australia.

[14]. Sudjana, N., \& Ibrahim, R. (2001). Penelitian dan Penilaian Pendidikan. Bandung: Sinar Baru Algesindo.

[15]. Direktorat Jenderal Pendidikan Anak Usia Dini, Pendidikan Dasar dan Pendidikan Menengah Kementerian Pendidikan dan Kebudayaan. 2020. Data Pokok Pendidikan Dasar dan Menengah. Dikutip dari https://dapo.dikdasmen.kemdikbud.go .id 